\title{
HASIL DIAGNOSTIK MYCOBACTERIUM TUBERCULOSIS DARI SPUTUM PENDERITA BATUK $\geq 2$ MINGGUN DENGAN PEWARNAAN ZIEHL NEELSEN DI PUSKESMAS PANIKI BAWAH, TIKALA BARU DAN WONASA MANADO
}

\author{
${ }^{1}$ Maykel Sondak \\ ${ }^{2}$ John Porotu'o \\ ${ }^{2}$ Heriyannis Homenta
}

\author{
${ }^{1}$ Kandidat Skripsi Fakultas Kedokteran Universitas Sam Ratulangi Manado \\ ${ }^{2}$ Bagian Mikrobiologi Fakultas Kedokteran Universitas Sam Ratulangi Manado \\ Email: Maykelsondak12114@gmail.com
}

\begin{abstract}
Abstrak: Batuk merupakan salah satu gejala penyakit paru yang paling penting, tetapi kadang tidak diperdulikan. Batuk $\geq 2$ minggu perlu dicurigai karena merupakan gejala utama dari tuberkulosis paru terutama yang disertai dahak. Untuk mengetahui hasil diagnostik Mycrobacterium tuberkulosis pada sputum penderita batuk $\geq 2$ minggu dengan pewarnaan Ziehl-Neelsen di Puskesmas Paniki Bawah, Tikala Baru, dan Wonasa Manado. Desain penelitian yang digunakan adalah penelitian deskriptif dengan pengambilan sampel menggunakan cara total sampling pada kurun waktu september 2015 - Desember 2015. Pada pemeriksaan BTA pasien batuk $\geq 2$ minggu di Puskesmas Paniki ditemukan 2 pasien (11,76\%) positif dan 15 pasien $(88,24 \%)$ negatif, di Puskesmas Tikala Baru ditemukan 1 pasien (7,69\%) positif dan 12 pasien (92,31\%) negatif, dan di Puskesmas Wonasa tidak ditemukan BTA positif, presentase berdasarkan jenis kelamin dengan batuk lebih dari dua minggu terbanyak pada jenis kelamin laki-laki 21 (52,5\%) daripada perempuan 19 (47,5\%), sedangkan presentase usia dengan batuk lebih dari dua minggu terbanyak terjadi pada usia 55-79 tahun 37,5\%. Kesimpulan: Batuh lebih dari dua minggu merupakan gejala dari Tubekulosis paru dan paling sering diderita laki-laki dibandingkan perempuan pada kelompok usia 55-79 tahun.

Kata kunci: batuk lebih dari dua minggu, tuberculosis, BTA
\end{abstract}

\begin{abstract}
Cough is a symptom of lung disease which is very important, but sometimes ignored. Cough more than 2 weeks need to be taken seriously because it is the main symptom of pulmonary tuberculosis, especially when the cough is accompanied by phlegm. To determine the diagnostic results of mycrobacterium tuberculosis in the sputum of patients with cough $\geq 2$ weeks with Ziehl-Neelsen colouration in Puskesmas Paniki bawah, Tikala Baru, and Wonasa Manado. The study design used descriptive research by sampling method using total sampling during the period September 2015 - December 2015. patients with cough more than two weeks by checking the acid fast bacillus method in Paniki health center, we found 2 patients $(11,76 \%)$ with positive result and 15 patients $(88,24 \%)$ negative, whereas in Tikala found 1 patients (7,69\%) positive and 12 patients negative, in addition in Wonasa we don't find any positive patients. Percentage by sex with a cough for more than two weeks we found mostly male with 21 patients (52.5\%) while women only 19 patients $(47.5 \%)$. From the percentage of age with cough for more than two weeks mostly occurred in age 55-79 years old with percentage of $37.5 \%$.Conclusion: Cough more than two weeks is a symptom of lung Tubekulosis and most often affects males than females in the age group 55-79 years. Keywords: cough more than two weeks, tuberculosis, BTA
\end{abstract}


Batuk adalah salah satu cara untuk membersihkan saluran pernapasan dari lendir dan benda asing.Sebagian besar batuk diakibatkan rangsangan pada saluran pernapasan bagian bawah ditimbulkan oleh benda asing. Batuk juga merupakan salah satu gejala penyakit paru yang paling penting, tetapi relatif tidak spesifik. Batuk merupakan masalah serius yang kadang tidak diperdulikan. ${ }^{1}$ Batuk yang lebih dari dua minggu perlu dicurigai karena merupakan gejala utama dari tuberkulosis paru terutama yang disertai dahak. ${ }^{3}$

Tuberkulosis (TB) adalah penyakit infeksi menular yang disebabkan oleh bakteri Mycobacterium tuberkulosis. Bakteri ini lebih sering menginfeksi organ paru (80\%) dibandingkan dengan organ lainnya. ${ }^{3,4}$ Pasien dengan TB paru biasanya disertai batuk berdahak selama 2-3 minggu atau lebih. Batuk dapat diikuti dengan gejala tambahan yaitu dahak bercampur darah, batuk darah, sesak nafas, badan lemas, napsu makan menurun, berat badan menurun, malaise, berkeringat pada malam hari tanpa kegiatan fisik, demam lebih dari satu bulan.TBC paru biasanya menyerang usia produktif dan kalangan ekonomi rendah dengan tingkat pendidikan rendah. ${ }^{2,5}$

Diagnosik TB dapat ditegakkan melalui pemeriksaan mikroskopis BTA pada sputum penderita. Jika TB paru dideteksi secara dini dan diobati secara tuntas maka penderita TB paru dapat cepat menjadi non-infeksius dan akhirnya sembuh. Oleh karena itu, diagnosis memegang peran penting dalam pengendalian infeksi TB di komunitas. ${ }^{2}$

Pewarnaan BTA dapat dilakukan dengan metode Tan Thiam Hok, ZiehlNeelsen, atau Fluorokrom.Berdasarkan ketiga metode tersebut, fluorokrom memliki sensitivitas yang paling tinggi dibanding dua metode pewarnaan lainnya.Tetapi karena metode tersebut memerlukan peralatan yang sangat mahal sehingga sulit untuk dapat dilaksanakan di sarana kesehatan dengan fasilitas sederhana. Oleh karena itu, metode pewarnaan Ziehl Neelsen merupakan pilihan metode yang cukup sederhana dan memberikan sensitivitas dan spesifisitas yang cukup tinggi. ${ }^{6,7}$

Tuberkulosis (TB) merupakan masalah kesehatan masyarakat yang penting di dunia ini.Pada tahun 1992 World Health Organization (WHO) telah mencanangkan tuberkulosis sebagai Global Emergency.Laporan WHO tahun 2009 menyatakan bahwa terdapat 8,9 - 9,9 juta kasus tuberkulosis secara global.Setiap detik ada satu orang yang terinfeksi tuberkulosis di dunia ini, dan sepertiga penduduk dunia telah terinfeksi kuman tuberkulosis. Jumlah terbesar kasus TB terjadi di Asia tenggara yaitu 35\% dari seluruh kasus TB di dunia. ${ }^{2}$

Jumlah penderita TB paru di Indonesia merupakan jumlah persentase kelima terbesar di dunia. ${ }^{2}$ Dan biasanya $20 \%$ lebih tinggi pada laki- laki dibandingkan perempuan, tiga kali lebih tinggi dipedesaan dibandingkan perkotaan dan empat kali lebih tinggi pada pendidikan rendah dibandingkan pendidikan tinggi. Berdasarkan Kesehatan dasar tahun 2013 di Sulawesi utara, tercatat kurang lebih 6889 orang atau 0,3 \% dari total penduduk mengidap TB dan di Manado terdapat 1198 orang terdiagnosis TB. ${ }^{5,8}$

Berdasarkan uraian di atas, masih banyak terdapat kasus TB paru yang terdapat di Indonesia. Oleh karena itu, penulis tertarik untuk melakukan penelitian identifikasi Mycobacterium tuberculosis dari sputum penderita batuk $\geq 2$ minggu dengan pewarnaan Ziehl-Neelsen di Puskesmas Manado agar supaya TB paru dapat dideteksi dan ditanggulangi secara dini sehingga, dapat menurunkan kasus TB Paru di Indonesia terutama di Kota Manado.

\section{METODE PENELITIAN}

Penelitian deskriptif untuk mengetahui hasil diagnostic Mycrobacterium tuberkulosis dari sputum penderita batuk $\geq$ 2 minggu dengan pewarnaan Ziehl-Neelsen di Puskesmas Paniki Bawah, Puskesmas Tikala Baru, dan Puskesmas Wonasa 
Manado dengan pengambilan sampel menggunakan total sampling pada kurun waktu September 2015-Desember 2015.

\section{Alat dan Bahan Penelitian}

Alat: Mikroskop, Lampu Spritus, Gelas objek, Ose, Pot Sputum steril, pulpen, buku, Masker dan Sarung Tangan. Bahan : Sputum, Carbol fuchsin 0,5\%, Asam alkohol 3\%, Methylen Blue 0,5 \%, Minyak emersi.

\section{Cara Kerja}

Pengambilan sputum diambil tiga kali, yaitu dahak sewaktu - pagi - sewaktu kemudian sampel yang diperoleh dilakukan pewarnaan Ziehl Neelsen, pertama Pakailah alat perlindungan diri, Sediakan alat dan bahan yang akan digunakan, Ambil sebuah kaca sediaan yang bersih, bebas lemak dan tidak ada goresan., Lampu spritus dinyalakan dan ose dipanaskan sampai membara, Dinginkan ose yang dipanaskan lalu masukan kedalam pot sputum yang berisi material kuman cair, Sputum diratakan pada kaca sediaan, Tangkai ose yang digunakan tadi disterilkan dengan lampu spritus, Fiksasi preparat dengan melewatkan preparat di atas lampu spritus sebanyak 3x selama 3-5 detik, agar kuman menempel pada kaca sediaan, Letakan sediaan di atas rak pewarnaan, Tuangkan Carbol Fuchsin menutupi seluruh permukaan kaca sediaan selama 5 menit, Panaskan kaca sediaan secara hati-hati dengan cara melewatkan pada lampu spritus sampai keluar uap. Jangan sampai mendidih karena carbol fuchsin akan berbentuk kristal dan kuman akan rusak, Sediaan dibiarkan hingga dingin selama 5 menit, Sediaan dicuci dengan air mengalir secara hati-hati, Tuangkan asam alkohol di atas kaca sediaan sampai warna merah dari fuchsin hilang (maksimal 3 menit), Sediaan dicuci dengan air mengalir, Tuangkan larutan methylen blue $0,3 \%$ di atas sediaan dan biarkan selama 20-30 detik, Sediaan dicuci dengan air mengalir dan keringkan pada suhu kamar, dan Tetesi dengan minyak emersi dan amati di bawah mikroskop dengan perbesaran 1000x

\section{HASIL PENELITIAN}

Penelitian yang dilakukan di Puskesmas Paniki Bawah, Tikala Baru, dan Wonasa pada pengambilan sampel pada September - Desember 2015.

Tabel 1. Distribusi pasien berdasarkan jenis kelamin.

\begin{tabular}{ccc}
\hline Jenis Kelamin & Jumlah & $\mathbf{\%}$ \\
\hline Laki-Laki & 21 & $52,5 \%$ \\
Perempuan & 19 & $47,5 \%$ \\
Total & $\mathbf{4 0}$ & $\mathbf{1 0 0 \%}$ \\
\hline
\end{tabular}

Pada Tabel 1 batuk lebih dari dua minggu paling sering terjadi pada laki-laki (52,5\%) dibandingkan perempuan (47,5\%).

Tabel 2. Distribusi pasien berdasarkan usia

\begin{tabular}{ccc}
\hline Usia & Jumlah & $\mathbf{\%}$ \\
\hline 15-35 Tahun & 12 & $30 \%$ \\
36-55 Tahun & 13 & $32,5 \%$ \\
56-79 Tahun & 15 & $37,5 \%$ \\
Total & $\mathbf{4 0}$ & $\mathbf{1 0 0} \%$ \\
\hline
\end{tabular}

Pada Tabel 2 penderita batuk lebih dari dua minggu paling banyak ditemukan pada usia 56-79 tahun (37,5\%)

Tabel 3. Hasil pemeriksaan BTA di Puskesmas Paniki

\begin{tabular}{ccc}
\hline Hasil Penelitian & Jumlah & $\mathbf{\%}$ \\
\hline BTA $(+)$ & 2 & $11,7 \%$ \\
BTA $(-)$ & 15 & $89,3 \%$ \\
Total & $\mathbf{1 7}$ & $\mathbf{1 0 0 \%}$ \\
\hline
\end{tabular}

Pada pemeriksaan BTA pasien batuk lebih dari dua minggu di Puskesmas Paniki ditemukan 2 pasien (11,76\%) positif dan 15 pasien $(88,24 \%)$ negative.

Tabel 4. Hasil pemeriksaan BTA di Puskesmas Tikala Baru

\begin{tabular}{ccc}
\hline Hasil Penelitian & Jumlah & $\mathbf{\%}$ \\
\hline BTA $(+)$ & 1 & $7,6 \%$ \\
BTA $(-)$ & 12 & $92,4 \%$ \\
Total & $\mathbf{1 3}$ & $\mathbf{1 0 0 \%}$ \\
\hline
\end{tabular}

Pada pemeriksaan BTA pasien batuk 
lebih dari dua minggu di Puskesmas Tikala Baru ditemukan 1 pasien (7,69\%) positif dan 12 pasien (92,31\%) negatif.

Tabel 5. Hasil pemeriksaan BTA di Puskesmas Wonasa

\begin{tabular}{ccc}
\hline Hasil Penelitian & Jumlah & $\mathbf{\%}$ \\
\hline BTA (+) & 0 & 0 \\
BTA (-) & 10 & $100 \%$ \\
Total & $\mathbf{1 0}$ & $\mathbf{1 0 0 \%}$ \\
\hline
\end{tabular}

Pada pemeriksaan BTA pasien batuk lebih dari dua minggu di Puskesmas Wonasa tidak ditemukan BTA positif.

\section{BAHASAN}

Penelitian ini bertujuan untuk mengetahui Hasil Diagnostik Mycobacerium tuberculosis dari sputum penderita batuk lebih dari duaminggu di Puskesmas Paniki, Tikala Baru dan Wonasa. Penelitian sesuai kriteria inklusi ditemukan total 40 pasien yang datang berobat ke puskesmas pada November hingga Desember 2015, dimana terdiri atas 17 pasien dari Puskesmas Paniki, 13 pasien dari Puskesmas Tikala Baru, dan 10 pasien dari Puskesmas Wonasa.

Hasil penelitian yang diperoleh dari pasien dengan gejala batuk lebih dari dua minggu tertinggi terjadi pada laki-laki dibandingkan perempuan. Hal ini sesuai dengan penelitian yang dilakukan oleh Wen Ying Ting, dkk tahun 2014 menyatakan bahwa BTA positif lebih sering terjadi pada laki-laki 52,4\% dibandingkan pada perempuan 47,6\%. ${ }^{9}$ Penelitian ini juga sebanding dengan penelitian yang dilakukan oleh Giri Tricahyono pada masyarakat Surakarta yang menyatakan bahwa BTA positif lebih sering pada lakilaki (58,5\%) dibandingkan perempuan $(41,5 \%){ }^{10}$

Banyaknya jumlah kejadian TB paru yang terjadi pada laki-laki disebabkan karena laki-laki memiliki mobilitas yang tinggi dari perempuan sehingga kemungkinan tepapar lebih besar, selain itu kebiasaan merokok dan mengkonsumsi alkohol dapat memudahkan laki-laki terinfeksi TB paru karena merokok tembakau dan minum alkohol dapat menurunan sistem pertahanan tubuh, sehingga lebih mudah terinfeksi agent penyebab TB. ${ }^{11,12}$

Pada Table 4.2 penderita batuk yang lebih dari dua minggu lebih sering terjadi pada usia 56-79 tahun sebanyak 15 kasus (37,5\%) dari 40 kasus suspek TB yang ditemukan, ini dapat disebabkan karena pada usia lebih dari 55 tahun terjadi penurunan ketahanan tubuh yang menyebabkan tubuh rentan terhadap penyakit. $^{12}$ Penelitian ini berbanding terbalik jika dibandingkan dengan penelitian yang dilakukan oleh munir SM, Nawas A, Soetoyo DK di Departemen Pulmonologi dan Ilmu Kedokteran Respirasi Fakultas Kedokteran Universitas Indonesia, dimana angka kejadian tertinggi justru terjadi pada usia produktif yaitu usia 25 - 34 tahun dengan jumlah kasus sebanyak 36 kasus (35,6\%) dari 101 kasus suspek TB. ${ }^{13}$ Dalam penelitian ini tingginya kasus pada usia produktif kemungkinan disebabkan karena pada usia produktif ( 15 - 55 tahun) seseorang akan lebih sering melakukan kegiatan seperti berkerja, belajar, ataupun kegiatan lainnya. Seseorang yang melakukan banyak aktivitas akan lebih sering berinteraksi dengan orang lain dan lingkungan, interaksi ini dapat meningkatkan kemungkinan terjadinya penularan bakteri TB.$^{14}$

Distribusi hasil pemeriksaan BTA penderita batuk lebih dari dua minggu di Puskesmas Paniki dengan hasil positif sebanyak 2 kasus (11,76\%).Sedangkan BTA positif di Puskesmas Tikala Baru sebanyak 1 kasus (7,69\%).Jika dibandingkan dengan profil puskesmas Tikala Baru pada tahun 2014, BTA positif di puskesmas ini berkisar pada 9,19\%. Dapat dilihat bahwa presentase pasien dengan BTA positif di puskesmas Tikala Baru terjadi penurunan, tetapi karena profil puskesmas ini dibuat dalam kurun waktu satu tahun sedangkan penelitian yang saya lakukan hanya empat bulan maka presentase ini tidak dapat dijadikan acuan 
bahwa terjadinya penurunan pasien dengan BTA positif di Puskesmas Tikala Baru.

Berbeda dengan kedua puskesmas di atas, Puskesmas Wonasa justru tidak ditemukan hasil dengan BTA positif, padahal berdasarkan profil puskesmas pada tahun 2014 kasus BTA positif sebanyak 9,77\% . Hal ini dapat disebabkan karena waktu penelitian yang singkat sehingga tidak ditemukan BTA positif di puskesmas ini.

\section{DAFTAR PUSTAKA}

1. Slamet $H$, Muhammad A, Jusuf $M$, Helmia H. Dasar-Dasar Diagnostik Fisik Paru. Departemen Pulmonologi \& Ilmu Kedokteran Respirasi Fakultas Kedokteran Universitas Airlangga. Surabaya 2012: 4-5

2. Fattiyah I. Tuberkulosis Pedoman Diagnosis dan Penatalaksanaan Di Indonesia. Perhimpunan Dokter Paru Indonesia. Jakarta 2011;1-7

3. Pharmatical Care. Direktorat Bina Farmasi Komunitas dan Klinik Direktorat Jendral Bina Kefarmasian dan Alat Kesehatan.. Departemen KesehatanRI. 2005;2 diambil dari : http://binfar.kemkes.go.id/v2/wpconte nt/uploads/2014/02/PC_TB.pdf

4. Retno AW. Patofisiologi, Diagnosis, dan Klasifikasi Tuberkulosis. Departemen Ilmu Kedokteran Komunitas, Okupasi, dan Keluarga E-journal FK UI. http://staff.ui.ac.id/ system/files/users/retno.asti/material/ patodiagklas.pdf

5. Valen FS, Damajanty HCP, Frenly MU. Hubungan Antara Pengetahuan Dan Sikap Dengan Tindakan Hidup Sehat Pasien TB Paru Di POLIKLINIK PARU RSUP PROF DR. R. D KANDOU MANADO. 1 Agustus 2013;3;5

6. Karuniawati A, Risdiyani Y, Nilawati S, Prawoto, Rosana Y, Parwati I, dkk. Perbandingan TAN THIAM HOK, ZIEHL NEELSEN Dan FLUOROKROM Sebagai Metode Pewarnaan BasilTahan Asam Untuk Pemeriksaan Mikroskopik Sputum. Makara, Kesehatan, Vol. 9, No. 1,
Juni 2005: 29-33

7. Edward R. Buku Saku Hitam Kedokteran Paru. Permata Puri Media cetakan I. Jakarta 2012;223

8. Rumangan WR, Palandeng $H$, Rombot $D$. Gambaran Otopsi Verbal Pasien yang Meninggal Karena Tuberkulosis di Manado. Journal Kedokteran Komunitas dan tropic. 1 Febuari 2015;49

9. Ting WY, Huang SF, lee MC, Lin YY, Lee YC, Feng JY, dkk. Gender Disparities in Latent Tuberculosis Infection in High-Risk Individuals: A Cross-Sectional Study. Journal Plus One. 4 November 2014;9:1-8

10.Tricahyono G. Evaluasi ketepatan terapi pada pasien tuberculosis dibalai besar kesehatan paru masyarakat Surakarta bulan Januari- Juni 2013.E-Journal Universitas Muhamadiyah Surakarta. http://eprints.ums.ac.id/31196/13/NA SKAH_PUBLIKASI.pdf

11.Hiswani. Tuberkulosis Merupakan Penyakit Infeksi Yang Masih Menjadi Masalah Kesehatan Masyarakat. E-Journal FK USU; 4 diambil dari http://repository.usu.ac.id/bitstream/1 23456789/3718/1/fkm-hiswani6.pdf

12.Dotulong JF, Sapulete MR, Kandou GD. Hubungan Faktor Resiko Umur, Jenis Kelamin, dan Kepadatan Hunian dengaKejadian TB Paru di Desa Wori Kecamatan Wori. Journal kedokteran komunitas dan tropic, Vol 3 No 2, 2 April 2015;60

13.Munir SM, Nawas A, Soetoyo DK. Pengamatan Pasien Tuberkulosis Paru dengan Multidrug Resistant (TBMDR) di Poliklinik Paru RSUP Persahabatan. Respirasi Indonesia.Journal Respirasi Indonesia Vol 30, No.2, 2010;30:92-104

14.Aandi I. Hubungan Tingkat Sirkulasi Oksigen dan Karateristik Individu dengan Kejadian TB Paru pada Kelompok Usia Produktif di Puskesmas Pondok Pucung Tahun 2013. E-journal Universitas Islam Negri Jakarta. 2013. http://repository. uinjkt.ac.id/dspace/bitstream/1234567 89/26505/1/Muhammad\%20Aandi\%2 OIhram-FKIK.pdf. 